\section{Narrativas digitais e estruturas circulares}

\section{RESUMO}

Este artigo aborda as narrativas literárias e a poesia criada e disponibilizada pelos meios digitais de informação. A autora indica alguns aspectos característicos desse tipo de narrativa, como a hibridação e a não-linearidade e, ainda, analisa a idéia de estrutura circular da narrativa como um elemento fundamental na sua concepção. Busca na Poesia Concreta uma influência para a criação poética que se dá no ambiente digital, através, especialmente, das idéias dos teóricos concretos sobre o círculo e o ideograma.

\section{ABSTRACT}

This article analyses literary narratives and poetry created by and disseminated through digital means. Some characteristics of this kind of work are hybridization and nonlinear narratives. The author also analyses the concept of circular structure deployed by the new narratives, regarding that as a fundamental element in their ideation. She looks for, through Concrete Poetry, the main paradigm influencing literary practice in the digital enviroment, closely examining its relationship with ideas developed earlier by theoretical concretists about the circle and the ideogram.

\section{PALAVRAS-CHAVE / KEY-WORDS \\ - Narrativa (Narrative) \\ - Arte digital (Digital art) \\ - Criatividade (Creativity)}

\section{Raquel Ritter Longhi}

Mestre em Comunicação e Informação UFRGS
As CRIAÇÕES LITERÁRIAS que se dão nos meios digitais são diferenciadas por vários aspectos notáveis. Primeiramente, há neste ambiente uma espécie de hibridação: as formas poéticas abarcam poesia e prosa, assim como abarcam um universo de representações que vão desde a palavra até o som, passando por toda espécie de imagem, em movimento ou não. Além disso, a estrutura destas narrativas apresentase sob formas inovadoras. Neste sentido, a não-linearidade aparece como um de seus grandes diferenciais. Contrapondose à idéia de seqüências lógicas estabelecidas pelo princípio aristotélico da trama, com começo, meio e fim, aparece a ausência total destas instâncias. Ao invés de seqüência, repetições; ao invés de temporalidade, utilização do espaço virtual da tela do computador; ao invés de linha, círculo. Pensar este ambiente digital de criação é também um exercício rumo à história das rupturas literárias e de movimentos como o da Poesia Concreta, que anteciparam idéias que hoje refletemse nas criações poéticas dos meios digitais.

O poeta Octavio Paz estabeleceu uma diferença entre poesia e prosa que inspira nossas reflexões acerca das criações literárias que se dão nos meios digitais. Observou que a figura geométrica que simboliza a prosa é uma linha: "reta, sinuosa, espiralada, ziguezagueante, mas sempre para diante e com uma meta precisa" (Paz, 1996). Já o poema, continua o poeta, apresenta-se como um círculo ou uma esfera, algo que se fecha sobre si mesmo.

Paz acentua o paradoxo entre as duas formas. Nas narrativas que têm lugar nos meios digitais, vemos uma hibridação entre o que seriam as formas da prosa e as da poesia. À idéia de linha reta, com uma meta definida, que o autor confere 
à prosa, contrapõe-se a narrativa em hipertexto e hipermídia, por exemplo: nãolinear ou multilinear, com vários e nenhum objetivo ao mesmo tempo, aberto a várias possibilidades.

É precisamente quando o poeta acentua a característica de poesia de obras em prosa como Alice no País das Maravilhas, de Lewis Caroll, ou O Jardim dos Caminhos que se Bifurcam, de Jorge Luis Borges, que podemos compreender mais claramente a relação de hibridação destas formas e trazê-las para o contexto das narrativas digitais. Ora, vários autores já notaram a estrutura multilinear do conto de Borges, e não é à toa que Paz usa este exemplo. Ele chega a observar que, nas obras citadas, a prosa se nega a si mesma. Ele continua: "As frases não se sucedem obedecendo a uma ordem conceitual ou narrativa, mas são presididas pelas leis da imagem e do ritmo. Há um fluxo e refluxo de imagens, acentos e pausas, sinal inequívoco de poesia" (Paz, 1996: 15).

Discussões como esta são agora trazidas à luz do debate sobre as narrativas em hipertexto, por exemplo em autores como George Landow, J. David Bolter ou Janet Murray, numa tentativa de retomar criticamente tais obras, para com isso avaliar a importância das rupturas trazidas pelo ambiente de escrita digital. Quando Paz afirma que Alice... e $\mathrm{O}$ jardim... têm características do poema, porque concebidos à luz das imagens e do ritmo, isto nada mais é do que resgatar, nestas obras, uma qualidade sua que não era reconhecida, pelo menos, não de imediato. Acentuando a forma do poema na prosa, o poeta anuncia uma mescla entre estes dois conceitos. Tal mistura aparece claramente nas escrituras digitais, cuja hibridação de formas parece ser um elemento fundador.

\section{O círculo em suas partes}

Voltando mais precisamente ao círculo, vemos que esta imagem não parece estar fora de contexto quando o assunto é narrativa literária. Mais especificamente, ao círculo podem-se remeter, ainda, algumas das atuais formas narrativas contemporâneas, muitas delas criações que se dão no computador.

À luz desta forma geométrica, podese associar tanto seqüências quanto repetições, além de algo mais distintivo das atuais narrativas: o deslocamento e redefinição das instâncias de começo, meio e final. Na figura geométrica do círculo, não há começo nem final. Estas instâncias inscrevem-se em todos os pontos formadores da linha do círculo, podendo ser designados como tal aleatoriamente, sem qualquer ordenação prévia.

Nas narrativas chamadas "nãolineares", começos e finais podem existir, mas não se encontram claramente definidos, ou definidos a priori. Em sua já famosa ficção em hipertexto afternoon, a story (http://www.eastgate.com), o escritor Michael Joyce avisa aos navegadores que os começos e finais não estão dados de antemão naquela narrativa. $O$ escritor chega a esclarecer que o término da história pode estar simplesmente no momento em que o leitor se cansa e resolve "sair" ou "abandonar" aquela leitura. Se o leitor decidir por terminar a sua leitura em um determinado ponto, segundo Joyce, aí estaria o "final" da história. Estas instâncias, então, perdem sua natureza definidora especialmente em relação ao tempo da narrativa para fazer surgir uma outra estrutura, circular, em que os acontecimentos podem repetir-se, - leitor pode passar várias vezes por um determinado link, e assim "revisitar" partes da história. Dá-se, assim, uma estrutura cujo espaço narrativo supõe mais do que uma seqüência, uma relação entre suas partes.

O poeta Augusto de Campos $^{1}$ nos remete a esta rede de relações, com a idéia do ideograma, e também ao círculo, quando reflete sobre a presença fundadora de James Joyce e do poema Un coup de 
dés, de Mallarmé, para a gênese da Poesia Concreta. Nestas estruturas, diz o poeta, "o contraponto é moto-perpétuo, o ideograma é obtido através de superposições de palavras, verdadeiras 'montagens' léxicas.

A infra-estrutura geral é um desenho circular, onde cada parte é começo, meio e fim". ${ }^{2}$

Pensar na forma do poema como um espaço de associações foi um dos principais fundamentos da poesia concreta. Uma das chaves mais importantes para se entender esta valorização da estrutura visual do poema, sem dúvida, parece estar no ideograma chinês, inspirador dos poetas concretos, tanto no sentido de sintaxe espacial ou visual, até o de método de compor baseado na justaposição direta, inspirado pelos estudos de Fenollosa e de Pound. ${ }^{3}$ Em tais associações, as seqüências lógicas são abolidas, em nome de "uma organização poético-gestaltiana, poético-musical, poético-ideogrâmica da estrutura". ${ }^{4}$

A comprovar a existência de uma estrutura circular, ainda, estão as próprias palavras textuais de algumas obras: em "Finnegans Wake", lembra Campos, a frase inicial é a continuação da última frase, e várias outras frases ligam-se a sentenças anteriores ou posteriores neste sentido - enquanto que no poema fundador de Mallarmé, as derradeiras palavras também são as primeiras: Toute pensée é met un coup de dés. Augusto de Campos, aliás, faz um estudo minucioso a respeito da presença do poema de Mallarmé no Finnegans Wake, de Joyce ${ }^{5}$, e conclui que ambos, o poema e o romance, "chegaram a uma concepção de obra 'circular', onde o princípio, o meio e o fim adquirem relatividade perene".

Esta estrutura "circular", no que concerne ao Finnegans Wake, já havia sido apontada também por Haroldo de Campos. Em seu artigo A Obra de Arte Aberta, o autor sustenta que "o Finnegans retinha a propriedade do círculo, da eqüidistância de todos os pontos em relação ao centro: a obra é porosa à leitura por qualquer das partes através das quais se procure assediá-la...".6

Estes começos e finais que se imbricam num todo a formar um motoperpétuo também estão presentes em outras formas narrativas: aqueles que assistiram a Antes da Chuva ${ }^{7}$, por exemplo, não poderão esquecer da circularidade daquela narrativa episódica. Nesta bela história, o primeiro capítulo parece tomar um outro significado ao término do último fotograma, no último capítulo, portanto, quando se percebe sua estreita ligação - ademais, marcada pela existência de referências temporais - com o capítulo final. É neste surpreendente final que se fecha o círculo; é aí que o espectador parece voltar ao começo da história, interconectandose nesta linha circular e ao mesmo tempo eliminando qualquer seqüência temporal até então experimentada. O sentido, aí sim, parece tomar forma neste "fechamento" do círculo, que não é mais do que a abertura para a ausência de seqüência lógica.

Paradoxal? Não, apenas a riqueza de uma estrutura narrativa que abole convenções e busca no espectador a parte que lhe falta. Obra que se completa com seu fruidor, círculo que se fecha com a ação de ver.

Se Joyce, Pound e Mallarmé foram inspiradores para os concretistas, hoje a Poesia Concreta é uma referência para se pensar na criação poética que se dá nos ambientes digitais. Ainda mais, levandose em conta as características deste suporte, especialmente a possibilidade de disponibilidade criativa de forma não-linear. Depreende-se disto, e ainda utilizando as referências da teoria da poesia concreta, que a não-linearidade, enfim, possa ser pensada em termos de relações entre blocos de informação, ou fragmentos. Levando em consideração que a estrutura não-linear do meio digital é onipresente, devido mesmo à sua natureza, talvez seja interessante refletir sobre o que ela representa para a criação poética em 
computador.

\section{Computador, espaço de escrita}

Em primeiro lugar, pensemos neste espaço de escrita que é a tela, e nas possibilidades de disponibilidade do texto poético. Estamos nos referindo a um espaço capaz de abrigar a palavra em diversas formas, que podem incluir inclusive seu movimento, sua animação. Dentre esta multiplicidade de manejos da palavra, ainda se encontra sua própria combinação com os espaços em branco, ou com outros espaços (acionáveis com o clique do mouse, muitas vezes, ou espaços que simplesmente surgem do nada, vindos de alguma reserva virtual de informação digitalizada) dentro deste espaço maior, que é a tela.

O poeta André Vallias, no seu hiperpoema "Nós não entendemos Descartes" (http://www.refazenda.com.br/ aleer), mostra, figurativamente, a prosa e o poema, partindo da relação entre página e poema. Neste exercício, transcende esta relação para o espaço tridimensional da tela do computador que, enfim, se transforma no novo "campo de significação do poema". 8

A não-linearidade parece implicar necessariamente uma abolição do sentido de tempo, pelo menos naquela temporalidade explícita existente na seqüência lógica aristotélica das narrativas com começo-meio-fim. No espaço da hipermídia, a temporalidade assume um outro estatuto. O tempo da técnica, como disse Octavio Paz (1996), é a abolição do tempo cronométrico moderno. No que concerne à Poesia Concreta, por exemplo, a utilização das categorias espaço e tempo veio introduzir uma outra relação com a criação poética: "espaço qualificado: estrutura espaço-temporal, em vez de desenvolvimento meramente temporísticolinear". ${ }^{9}$ A referência à temporalidade, quando se fala em não-linearidade, é, para estes autores, portanto, fundamental, e, se tomarmos as criações poéticas ao longo da história da literatura, veremos que não é diferente: as rupturas com as formas lineares de disponibilidade do poema vêm marcadas pela organização espaçotemporal e valorização da forma. Um exemplo está em Mallarmé, que se utilizou dos espaços em branco da página e das diferentes fontes e tamanhos de letras no já citado Un coup de dés.

Tal valorização do espaço como estrutura de significação, assim, é a instituição de uma outra seqüência de leitura, não mais marcada pela linearidade antes consagrada à lógica das leituras, mas, enfim, trazida para o leitor como série de possibilidades. Assim, por exemplo, é o poema verbi-voco-visual, sujeito por excelência da poesia concreta, que se compõe de elementos estruturais e de significado que vão muito além da linearidade...

Há, portanto, neste ambiente de escrita virtual que é a tela do computador, não-linearidades em potencial, ou seja, possibilidades dadas a fim de serem atualizadas. Cabe ao leitor efetuar esta relação entre os elementos. Trata-se de alternativas virtuais de seguimentos do texto, ou do poema, ou seja, algo que existe mas não está presente, para usar uma expressão de Lévy (1999).

Mais uma vez, a leitura de Octavio Paz é estimulante:

“... o poema é um espaço vazio mas carregado de iminência. Ainda não é presença: é um conjunto de signos que procuram o seu significado e que não significam outra coisa além de ser procura”. (Paz, 1996: 104).

\section{O espaço concreto}

O espaço virtual da tela do computador é capaz de dar forma concreta ao que a poesia concreta colocava como potência. Se na página impressa o poema era 
visto como possibilidades de relações ideogrâmicas, na tela digital estas possibilidades tomam concretude, entre outras coisas, pelas possibilidades de animação textual da hipermídia. Temos um exemplo simples - apenas uma transposição para este ambiente - mas ilustrativo, no poema Life (1957), de Décio Pignatari, disposto na tela do computador (http://www.dialdata.com.br/casadasrosas/ desexp/decio/).

As letras L, I, F e E, brancas sob um fundo negro, vão formando a imagem do poema, que então surge como figura animada: primeiro, o I que em menos de um segundo transforma-se em $L$, que, estranhamente fora de "seqüência", parece completar a letra anterior, sobrepondose a ela de modo quase imperceptível. Seguem-se o $\mathrm{F}$ e o $\mathrm{E}$ que, como no caso das primeiras duas letras, parecem completar-se, o $\mathrm{F}$ transformando-se quase imperceptivelmente num $E$, fechando-se em uma forma retangular, como se tivesse recebido, para completar-se, o L e o I e o $\mathrm{F}$ imediatamente anteriores. Fecha-se o círculo, para logo voltar ao começo do poema animado.

O exemplo acima representa muito mais uma transposição de um poema do formato impresso para o digital, do que, propriamente, um poema criado pelo e para computador, mas serve para nosso raciocínio por tratar-se de poesia e das possibilidades que 0 meio digital oferece na sua disponibilidade. Neste poema, a animação das letras, que formam imagem, atua em uma rede de relações entre suas partes, resultando assim em um novo significado. $O$ que elaboramos a partir de associações mentais, quando lemos Life na página impressa, vemos tomar forma concreta na tela do computador: constatamos que tais associações, afinal, estão representadas organicamente neste ambiente.

Atualização e não-linearidade
Começos, meios e finais podem estar muito mais relacionados com a narrativa em prosa do que, especialmente, com a poesia. Mas, quando se pensa em criação poética no computador, duas questões aparecem: a primeira, refere-se à hibridação entre estas duas formas, como já foi citado anteriormente. Em segundo lugar, a idéia de inter-relação entre as partes. Os elementos (textuais, imagéticos, sonoros, etc.) são dados e disponibilizados de forma simultânea e atualizados pela ação do leitor. As possibilidades do hipertexto e da hipermídia, então, passam a fazer diferença para a criação poética. Arlindo Machado ${ }^{10}$ atenta para o que define como "arquitetura não-linear" da hipermídia. Ele diz que:

"A idéia básica da hipermídia é aproveitar a arquitetura não-linear das memórias de computador para viabilizar 'obras' tridimensionais, dotadas de uma estrutura dinâmica que as torne manipuláveis interativamente". O hipertexto, neste sentido, seria "um texto escrito no eixo do paradigma, ou seja, um texto que já traz dentro de si várias outras possibilidades de leitura e diante do qual se pode escolher dentre várias alternativas de atualização (...)". ${ }^{11}$

O dado fundamental a respeito da "arquitetura não-linear" talvez resida no fato de que não importa a forma - prosa ou poesia -, a possibilidade de atualização de suas partes e assim, de sua inter-relação, é um dos diferenciais deste tipo de criação em computador.

Ao refletir sobre o hibridismo das formas e a estrutura circular podemos vislumbrar pelo menos três pontos importantes para a compreensão da criação poética no computador: o primeiro diz respeito a uma rede de relações entre as partes, sendo estas letras, espaços, frases, conjuntos de palavras e mesmo conteúdos.

$\mathrm{O}$ segundo refere-se à existência da 
não-linearidade como princípio gerativo da criação, pois aquela inscreve-se dentro das próprias características físicas do meio digital, ou seja, uma das características com que o poeta pode contar quando cria com o computador.

Colocada ainda no âmbito das possibilidades do poema, a não-linearidade pode ser definidora de uma estrutura espacial em que são possíveis as relações entre as partes, ou seja, as associações infinitas potencializadas pela disposição das partes do poema no espaço virtual do computador.

Em terceiro lugar, as realocações das instâncias de começos, meios e finais, que se embaralham, tornam-se indefinidas e assim sugerem uma estrutura em círculo.

A escrita criativa encontra na hipermídia e no hipertexto um espaço aberto à mescla de todas as formas poéticas, o que propicia uma verdadeira reinvenção da escrita e uma renovação das formas poéticas. Por outro lado, é visível que esta renovação, de certa forma, acontece como conseqüência de algo que já vinha sendo anunciado por movimentos como a Poesia Concreta, que é inspirador para se refletir sobre as novas formas da escrita nos meios digitais .

\section{Notas}

1 No artigo-manifesto "Pontos-periferia Poesia Concreta". In: Teoria da Poesia Concreta: textos críticos e manifestos. 1950-60. São Paulo: Livraria Duas Cidades, 1975, 2ª ed.

2 Conforme a leitura de Campos do artigo "A skeleton key to Finnegans Wake", de Joseph Campbell e Henry Morton Robinson. Faber \& faber, London, 1947. In: Panorama do Finnegans Wake, Augusto e Haroldo de Campos, São Paulo, ed. Perspectiva, $3^{\mathrm{a}}$ ed., 1986.

3 Teoria da Poesia Concreta: textos críticos e manifestos. 1950-60. São Paulo: Livraria Duas Cidades, 2ª ed., 1975.

4 Id., ib.
5 No artigo "O lance de dados do Finnegans Wake". In: Panorama do Finnegans Wake, Augusto e Haroldo de Campos, São Paulo, Perspectiva, $3^{a}$ ed., 1986.

6 Publicado no livro Teoria da Poesia Concreta: textos críticos e manifestos. 1950-60. São Paulo: Livraria Duas Cidades, $2^{\text {a }}$ ed., 1975.

7 Filme do diretor Milcho Manchevski, Macedônia, 1994.

8 Vallias conta sobre seu processo de criação deste e de outros poemas no artigo "We have not understood Descartes", na publicação Visible Language, editada por Eduardo Kac. (Visible Language, 3.2 (oct. 1996), pp. 150157).

9 Teoria da Poesia Concreta: textos críticos e manifestos. 1950-60. São Paulo: Livraria Duas Cidades, 1975, $2^{\mathrm{a}}$ ed.

10 No artigo "Formas expressivas da contemporaneidade", página 63. CD-Rom Ensaios sobre a contemporaneidade.

11 Id., ib., p. 57.

\section{Referências}

BOLTER, Jay D. Writing space: the computer, hypertext, and the history of writing. Hillsdale: Lawrence Erlbaum Associates, 1991.

CAMPOS, Augusto e HAROLDO de, e Décio PIGNATARI. Teoria da Poesia Concreta: textos críticos e manifestos. 1950-60. $2^{a}$ ed. São Paulo: Livraria Duas Cidades, 1975.

CAMPOS, Augusto e Haroldo de. Panorama do Finnegans Wake. $3^{\text {a }}$ ed. São Paulo: Perspectiva, 1986.

JOYCE, Michael. Afternoon, a story. Eastgate Systems, Cambridge: 1991. (disquete)

KAC, Eduardo (ed.) Visible Language, 3.2 (oct. 1996).

LANDOW, George. Hipertexto: la convergencia de la teoría crítica contemporánea y la tecnología. Barcelona: Paidós, 1995.

LÉVY, Pierre. Cibercultura. Trad. Carlos Irineu da Costa. Rio de Janeiro: Ed. 34, 1999. 
LONGINO, Horácio. A poética clássica: ARISTÓTELES; introdução por Roberto de Oliveira Brandão, tradução direta do grego e do latim por Jaime Bruna, 7a. ed. São Paulo: Cultrix, 1997.

MACHADO,Arlindo."Formas expressivas da contemporaneidade". In Ensaios sobre a contemporaneidade. PUC/SP, São Paulo, 1994. (CDRom).

MURRAY, Janet. Hamlet on the holodeck. The future of narrative in cyberspace. New York: Free Press, 1997.

PAZ, Octavio. Signos em rotação. $3^{a}$ ed. São Paulo: Perspectiva, 1996. 